\title{
Pengaruh Shift Kerja, Stres Kerja Dan Lingkungan Kerja Terhadap Kinerja Karyawan Di PT. Liku Telaga Gresik
}

\author{
Yani Elviani Lestari ${ }^{1}$, Moh. Bukhori ${ }^{2}$ Fathorrahman $^{3}$ \\ STIE ASIA Malang ${ }^{1,2,3}$
}

\begin{abstract}
In determining and achieving a goal in a organization, one element that's needed is human resource. In facing challenges to achieve organizational goals, continues improvement is needed to improve and enhance employee performance. The goals of this research is : 1. To know and analyze the impact of shift system to employee's performance, 2. To know and analyze the impact of employee's stress level to employee's performance, 3. To know and analyze the impact of work environment to employee's performance, 4. To know and analyze the impact of shift system, employee's stress level, and work environment simultaneously to employee's performance. This research is associative casual research using quantitative approach. This research was conducted on PT Liku Telaga's employees. The population of this research is all permanent employees of PT Liku Telaga. Samples were taken using proportional random sampling method from 68 respondents. Those data were processed using SPSS software ver.20. The result of this research shows that 1. Shift system doesn't affect significantly and affect positively to employee's performance 2. Employee's stress level affect significantly and affect negatively to employee's performance 3. Work environment affect significantly and affect positively to employee's performance 4. Shift system, employee's stress level and work environment affect significantly to PT Liku Telaga employee's performance.
\end{abstract}

Keywords: $\quad$ Shift Work, Job Stress, Work Environment, Employees Performance

\section{Pendahuluan}

Sumber daya manusia merupakan salah satu unsur vital dalam penentuan tujuan suatu organisasi. Dalam suatu organisasi, latar belakang pendidikan sumber daya akan beragam. Dengan keberagaman yang ada, diperlukan manajemen yang baik agar tujuan organisasi dapat tercapai. Sumber daya manusia merupakan organizational resource yang dapat meningkatkan kompetitif organisasi. Dalam menghadapi tantangan untuk mencapai tujuan organisasi diperlukan continues improvement. Salah satu wujud nyata perusahaan untuk melakukan continues improvement adalah memperbaiki dan meningkatkan kinerja karyawan. 
Menurut Mangkunegara (2009), kinerja adalah hasil kerja secara kualitas dan kuantitas yang dicapai oleh seorang karyawan dalam melaksanakan tugasnya sesuai dengan tanggung jawab yang diberikan kepadanya. Untuk mengatasi persoalan yang ada di sebuah organisasi, karyawan akan dihadapkan dengan tugas dan tanggung jawab sesuai dengan tuntutan akan profesinya. Di sisi lain, karyawan pasti memiliki keterbatasan atas apa yang dituntut dari profesinya. Untuk mengatasi hal tersebut, dibutuhkan manajemen untuk meningkatkan kinerja karyawan. Bila individu dalam perusahaan sebagai sumber daya manusia dapat berjalan efektif, maka perusahaan tetap berjalan efektif. Dengan kata lain, kelangsungan perusahaan ditentukan oleh kinerja karyawannya.

Sebagai salah satu industri kimia di Jawa Timur, PT. Liku Telaga terus berupaya memperbaiki dan meningkatkan kinerja karyawan sebagai salah satu tindakan continues improvement. PT. Liku Telaga merupakan industri kimia dasar yang memproduksi Sulfuric acid, Aluminium sulfate dan Sodium silicate. Jumlah karyawan tetap PT. Liku Telaga 191 karyawan tetap. Karyawan tetap di PT. Liku Telaga terbagi dalam sembilan divisi.

Faktor pertama yang mempengaruhi kinerja karyawan adalah shift kerja. Shift kerja merupakan pola waktu kerja yang diberikan pada karyawan untuk mengerjakan sesuatu dan umumnya dibagi atas kerja pagi, sore dan malam. Tidak semua orang dapat menyesuaikan diri dengan sistem shift kerja karena membutuhkan banyak penyesuaian waktu, seperti waktu tidur, waktu makan dan waktu berkumpul bersama keluarga. Sistem produksi kontinyu di PT. Liku Telaga membuat sistem kerja shift diberlakukan untuk karyawan. Sistem shift kerja PT. Liku Telaga adalah delapan jam kerja perhari satu shift dan waktu produksi tujuh hari. Setiap hari, PT. Liku Telaga terbagi dengan tiga shift kerja. Hasil penelitian Coffey, et. al. (1988) menyebutkan bahwa kinerja perawat tertinggi pada siang hari, diikuti dengan shift malam, shift sore dan pergantian shift. Stres terhadap pekerjaan juga didapatkan yang tertinggi adalah pergantian shift, diikuti dengan shift pada sore hari, siang hari dan malam hari. Dengan demikian, shift kerja berpengaruh terhadap kinerja dan stres yang berkaitan dengan pekerjaan serta bukan faktor lain. Kemudian Penelitian Chou dan Hsieh (2010) menunjukkan bahwa khususnya shift 
malam dapat memiliki dampak negatif pada kualitas tidur dan secara moderat menyebabkan kinerja kerja yang buruk

Faktor kedua yang mempengaruhi kinerja karyawan adalah stres kerja. Stres merupakan suatu kondisi keadaan seseorang mengalami ketegangan karena adanya kondisi yang mempengaruhinya. Kondisi tersebut dapat diperoleh dari dalam diri seseorang maupun lingkungan di luar diri seseorang. Penelitian Khuong dan Yen (2016) menunjukkan bahwa stres kerja yang berpengaruh negatif terhadap kinerja karyawan. Kemudian penelitian yang dilakukan oleh Dar, et. al., (2011) mengungkapkan bahwa terdapat hubungan negatif antara stres kerja terhadap kinerja karyawan dan menunjukkan bahwa stres kerja secara signifikan mengurangi kinerja pekerjaan karyawan. Lalu Penelitian Altangerel, et. al., (2015) menemukan bahwa kelebihan pekerjaan adalah alasan utama stres dan berdampak pada berkurangnya produktivitas dan kehilangan minat dalam bekerja. Hal berbeda ditunjukkan bahwa usia, banyaknya jumlah anggota keluarga, tidak adanya waktu bersantai yang diberikan pada karyawan selama jam kerja dan beban kerja secara statistik signifikan negatif pada kinerja karyawan.

Faktor ketiga yang mempengaruhi kinerja karyawan adalah lingkungan kerja. Kondisi lingkungan kerja yang baik akan mendorong inisiatif dan kreativitas sehingga menciptakan antusiasme untuk bersatu dalam organisasi perusahaan untuk mencapai tujuan perusahaan dengan meningkatkan kinerja karyawan. Menurut Nitisemito (2011), lingkungan kerja merupakan keseluruhan alat perkakas yang dihadapi, lingkungan sekitarnya di mana seseorang bekerja, metode kerjanya, serta pengaturan kerjanya baik sebagai perseorangan maupun sebagai kelompok. Penelitian pengaruh lingkungan kerja terhadap kinerja karyawan dilakukan oleh Malik, et. al., (2011) menunjukkan bahwa semua variabel independen memiliki hubungan yang kuat dan signifikan dengan kinerja karyawan, terutama kondisi kerja fisik yang mencerminkan hubungan positif dan signifikan paling kuat. Dimana kondisi fisik ini merupakan salah satu indikator dari lingkungan kerja. Kemudian penelitian Al-Omari dan Okasheh (2017) yang menyatakan bahwa elemen lingkungan kerja yang diteliti adalah kebisingan, suhu udara, penerangan, warna ruangan dan kepuasan kerja. Dari penelitian, ditemukan kendala situasional 
seperti kebisingan, fasilitas material kerja, ventilasi dan penerangan adalah kondisi lingkungan kerja utama yang memiliki dampak negatif pada kinerja karyawan dan harus mendapat perhatian khusus.

Oleh karena itu, dalam penelitian ini akan dibahas mengenai bagaimana pengaruh shift kerja, stres kerja, dan lingkungan kerja terhadap kinerja karyawan. Berdasarkan latar belakang diatas, maka rumusan masalahnya antara lain:

1. Apakah shift kerja berpengaruh terhadap kinerja karyawan?

2. Apakah stres kerja berpengaruh terhadap kinerja karyawan?

3. Apakah lingkungan kerja berpengaruh terhadap kinerja karyawan?

4. Apakah shift kerja, stres kerja dan lingkungan kerja berpengaruh secara simultan terhadap kinerja karyawan?

\section{Metode Penelitian}

\section{Pendekatan Penelitian}

Penelitian ini merupakan penelitian asosiatif kausal dengan menggunakan pendekatan kuantitatif. Penelitian asosoatif kausal adalah penelitian yang bertujuan untuk mengetahui pengaruh antara dua variabel atau lebih (Umar, 2005). Penelitian ini menjelaskan hubungan mempengaruhi dan dipengaruhi dari variabel-variabel yang diteliti. Penelitian ini menggunakan pendekatan kuantitatif karena data yang akan digunakan untuk menganalisis hubungan antar variabel dinyatakan dengan angka atau numerik (Kuncoro, 2003). Penelitian ini menganalisis pengaruh shift kerja, stres kerja dan lingkungan kerja terhadap kinerja karyawan di PT. Liku Telaga.

\section{Metode Pengambilan Sampel}

Populasi adalah jumlah keseluruhan semua anggota yang diteliti Sugiyono dalam (Satrio, 2015). Metode pengambilan sampel dalam penelitian ini menggunakan metode proposional random sampling. Random sampling (sampel acak) adalah suatu tipe pengambilan sampel secara acak. Jumlah sampel yang diambil dalam penelitian ini adalah 68 karyawan PT. Liku Telaga Gresik.

\section{Metode Pengumpulan Data}

Penelitian ini menggunakan metode pengumpulan data berupa observasi, wawancara dan kuesioner (angket). Observasi dilakukan untuk memperoleh 
informasi mengenai struktur organisasi PT. Liku Telaga, sehingga dapat diperoleh data yang dapat menunjang penelitian yang dilakukan. Wawancara juga dilakukan hanya kepada beberapa orang untuk memberikan informasi tambahan mengenai shift kerja, stres kerja, lingkungan kerja dan kinerja karyawan yang sedang diteliti. Kuesioner adalah teknik pengumpulan data melalui formulir yang berisi pertanyaan yang diajukan secara tertulis yang dibagikan kepada responden untuk mendapatkan jawaban atau tanggapan dan informasi yang diperlukan.

\section{Definisi Operasional Variabel}

Penelitian ini menggunakan dua jenis variabel yaitu variabel independen dan variabel dependen. Variabel independen yang digunakan: shift kerja, stres kerja dan lingkungan kerja. Variabel dependen yang digunakan: kinerja karyawan PT. Liku Telaga.Adapun definisi operasional variabel penelitian ini secara rinci disajikan dalam Tabel 1.

Tabel 1. Definisi Operasional Variabel

\begin{tabular}{|c|c|c|}
\hline Indikator & & Item \\
\hline \multicolumn{3}{|c|}{ Kinerja Karyawan } \\
\hline \multirow{2}{*}{$\begin{array}{l}\text { Perilaku } \\
\text { inovatif }\end{array}$} & Kinerja1 & $\begin{array}{l}\text { Saya mau melakukan usaha ekstra dalam menyelesaikan } \\
\text { pekerjaan dengan baik. }\end{array}$ \\
\hline & Kinerja2 & Saya berusaha lebih keras daripada seharusnya. \\
\hline \multirow{2}{*}{$\begin{array}{l}\text { Pengambilan } \\
\text { inisiatif }\end{array}$} & Kinerja3 & $\begin{array}{l}\text { Saya berusaha menemukan alternatif dalam memberikan layanan } \\
\text { kepada pelanggan. }\end{array}$ \\
\hline & Kinerja4 & Saya memberikan inisiatif dan kemandirian dalam bekerja. \\
\hline \multirow{2}{*}{$\begin{array}{l}\text { Tingkat } \\
\text { potensi diri }\end{array}$} & Kinerja5 & $\begin{array}{l}\text { Karyawan berusaha dengan lebih keras daripada yang } \\
\text { seharusnya. }\end{array}$ \\
\hline & Kinerja6 & $\begin{array}{l}\text { Saya menggunakan pengetahuan dan ketrampilan dengan baik } \\
\text { dalam bekerja. }\end{array}$ \\
\hline \multirow{2}{*}{$\begin{array}{l}\text { Manajemen } \\
\text { waktu }\end{array}$} & Kinerja7 & Ketepatan saya dalam melaksanakan pekerjaan bagus. \\
\hline & Kinerja8 & $\begin{array}{l}\text { Saya melakukan tugas yang diberikan dengan baik, seperti } \\
\text { menyimpan data dengan tepat, datang tepat waktu, dll. }\end{array}$ \\
\hline \multirow{2}{*}{$\begin{array}{l}\text { Pencapaian } \\
\text { kualitas dan } \\
\text { kuantitas } \\
\text { pekerjaan }\end{array}$} & Kinerja9 & Rata-rata kualitas hasil pekerjaan saya adalah tinggi. \\
\hline & Kinerja10 & Saya menyelesaikan tugas yang diberikan dengan baik. \\
\hline \multirow{2}{*}{$\begin{array}{l}\text { Kemampuan } \\
\text { diri untuk } \\
\text { mencapai } \\
\text { tujuan }\end{array}$} & Kinerja11 & $\begin{array}{l}\text { Kemampuan saya mencapai tujuan dan sasaran yang ditetapkan } \\
\text { adalah baik. }\end{array}$ \\
\hline & Kinerja12 & $\begin{array}{l}\text { Saya menyelesaikan pekerjaan dengan baik sesuai dengan tujuan } \\
\text { yang ditetapkan. }\end{array}$ \\
\hline
\end{tabular}


Relasi : Jurnal Ekonomi, Vol. 16, No. 1, Januari 2020, hlm. 208-230

\begin{tabular}{|c|c|c|}
\hline \multirow{2}{*}{\begin{tabular}{l}
\multicolumn{2}{c}{ Indikator } \\
Hubungan \\
rekan kerja \\
dengan \\
pelanggan
\end{tabular}} & \multicolumn{2}{|r|}{ Item } \\
\hline & Kinerja13 & Saya dapat bekerja sama dengan staf lain. \\
\hline $\begin{array}{l}\text { Pengetahuan } \\
\text { produk } \\
\text { perusahaan } \\
\text { dan produk } \\
\text { pesaing }\end{array}$ & Kinerja14 & $\begin{array}{l}\text { Pemahaman saya akan kebutuhan dan keinginan pelanggan } \\
\text { adalah tinggi. }\end{array}$ \\
\hline \multicolumn{3}{|l|}{ Shift Kerja } \\
\hline \multirow{3}{*}{$\begin{array}{l}\text { Pembagian } \\
\text { waktu shift }\end{array}$} & Shift1 & $\begin{array}{l}\text { Saya ditugaskan untuk menjalankan shift tertentu setelah } \\
\text { berunding dan diskusi. }\end{array}$ \\
\hline & Shift2 & $\begin{array}{l}\text { Saya menerima tugas dari atasan dengan masukan/saran dari } \\
\text { saya. }\end{array}$ \\
\hline & Shift3 & Saya puas dengan pembagian kerja shift saya \\
\hline $\begin{array}{l}\text { Pergantian } \\
\text { Shift }\end{array}$ & Shift4 & $\begin{array}{l}\text { Jika saya punya pilihan, saya akan memilih jam kerja (shift) yang } \\
\text { berbeda. }\end{array}$ \\
\hline \multicolumn{3}{|l|}{ Stres Kerja } \\
\hline \multirow{3}{*}{ Gejala fisik } & Stres1 & Secara umum saya biasanya tegang atau gugup. \\
\hline & Stres2 & $\begin{array}{l}\text { Saya selalu berkeringat ketika saya berpikir tentang pekerjaan } \\
\text { saya. }\end{array}$ \\
\hline & Stres3 & $\begin{array}{l}\text { Ada sejumlah saraf yang tegang yang terhubung dengan kegiatan } \\
\text { sehari-hari saya. }\end{array}$ \\
\hline $\begin{array}{l}\text { Gejala } \\
\text { perilaku }\end{array}$ & Stres4 & Kegiatan sehari-hari saya menyebabkan stres. \\
\hline \multirow{2}{*}{$\begin{array}{l}\text { Gangguan } \\
\text { psikologis }\end{array}$} & Stres5 & Saya sangat stres dalam berkomunikasi dengan orang lain. \\
\hline & Stres6 & Pada akhir bulan, saya benar-benar kelelahan mental dan fisik. \\
\hline \multirow{9}{*}{$\begin{array}{l}\text { Tuntutan } \\
\text { tugas }\end{array}$} & Stres7 & $\begin{array}{l}\text { Saya tidak bisa melakukan berbagai hal yang berbeda pada } \\
\text { pekerjaan saya. }\end{array}$ \\
\hline & Stres8 & Pekerjaan saya membutuhkan keterampilan yang sangat tinggi. \\
\hline & Stres9 & Pekerjaan saya sangat menuntut saya untuk belajar hal baru. \\
\hline & Stres10 & Pekerjaan saya menuntut saya untuk sangat kreatif. \\
\hline & Stres13 & $\begin{array}{l}\text { Saya tidak memiliki cukup waktu untuk mendapatkan pekerjaan } \\
\text { yang dilakukan. }\end{array}$ \\
\hline & Stres14 & Saya diminta untuk melakukan pekerjaan yang berlebih. \\
\hline & Stres15 & Pekerjaan saya membutuhkan bekerja dengan sangat cepat. \\
\hline & Stres16 & $\begin{array}{l}\text { Saya tidak bebas dari tuntutan yang membuat saling } \\
\text { bertentangan. }\end{array}$ \\
\hline & Stres17 & Pekerjaan saya membutuhkan bekerja dengan sangat keras. \\
\hline
\end{tabular}




\begin{tabular}{|c|c|c|}
\hline Indikator & \multicolumn{2}{|r|}{ Item } \\
\hline \multirow{2}{*}{$\begin{array}{l}\text { Struktur } \\
\text { organisasi }\end{array}$} & Stres11 & $\begin{array}{l}\text { Saya tidak bisa melakukan berbagai hal yang berbeda pada } \\
\text { pekerjaan saya. }\end{array}$ \\
\hline & Stres12 & Pekerjaan saya membutuhkan keterampilan yang sangat tinggi. \\
\hline \multicolumn{3}{|c|}{ Lingkungan Kerja } \\
\hline \multirow[b]{2}{*}{ Suasana kerja } & $\begin{array}{l}\text { Lingkunga } \\
\text { n1 }\end{array}$ & Suasana kerja mendukung setiap pekerjaan yang saya lakukan. \\
\hline & $\begin{array}{l}\text { Lingkunga } \\
\quad \mathrm{n} 2\end{array}$ & $\begin{array}{l}\text { Suasana kerja yang mendukung, dapat memicu saya dalam } \\
\text { mencapai standar kerja yang ditetapkan perusahaan, sehingga } \\
\text { hasilnya memuaskan. }\end{array}$ \\
\hline \multirow{2}{*}{$\begin{array}{l}\text { Hubungan } \\
\text { dengan kerja }\end{array}$} & $\begin{array}{l}\text { Lingkunga } \\
\text { n3 }\end{array}$ & $\begin{array}{l}\text { Hubungan kerja yang baik antara atasan dan bawahan membuat } \\
\text { saya bersemangat dalam bekerja. }\end{array}$ \\
\hline & $\begin{array}{l}\text { Lingkunga } \\
\text { n4 }\end{array}$ & $\begin{array}{l}\text { Hubungan kerja yang baik antar sesama karyawan membantu } \\
\text { saya dalam bekerja dan membuat betah di perusahaan. }\end{array}$ \\
\hline \multirow{2}{*}{ Fasilitas kerja } & $\begin{array}{l}\text { Lingkunga } \\
\mathrm{n} 5\end{array}$ & $\begin{array}{l}\text { Fasilitas yang ada di perusahaan sudah lengkap, sehingga } \\
\text { membuat saya nyaman dan betah dalam bekerja. }\end{array}$ \\
\hline & $\begin{array}{l}\text { Lingkunga } \\
\text { n6 }\end{array}$ & $\begin{array}{l}\text { Fasilitas kerja yang modern, membantu mempermudah setiap } \\
\text { pekerjaan yang saya lakukan. }\end{array}$ \\
\hline
\end{tabular}

\section{Metode Analisis Data}

\section{Uji Asumsi Klasik}

Uji normalitas bertujuan untuk menguji sampel yang digunakan mempunyai distribusi normal atau tidak. Pengujian normalitas data menggunakan Test of Normality Kolmogorov-Smirnov dalam program SPSS. Menurut Singgih Santoso (2012:293) jika probabilitas > 0,05, maka distribusi dari model regresi adalah normal.

Uji multikolinieritas digunakan untuk menguji apakah dalam model regresi ditemukan ada atau tidaknya korelasi antara variabel bebas. Untuk mendeteksi ada tidaknya multikolinieritas dapat dilihat dari besaran Variance Inflation Factor (VIF) dan Tolerance. Pedoman suatu model regresi yang bebas multikolinieritas adalah mempunyai angka tolerance mendekati 1. Batas VIF adalah 10, jika nilai VIF di bawah 10, maka tidak terjadi gejala multikolinieritas (Gujarati, 2012:432).

Uji heteroskedastisitas bertujuan untuk menguji terjadi atau tidaknya ketidaksamaan varians atau residual dari satu pengamatan ke pengamatan yang lain. Menurut Gujarati (2012:406) untuk menguji ada tidaknya heteroskedastisitas digunakan uji rank Spearman, jika nilai koefisien korelasi antara variabel independen dengan nilai residual signifikan, maka kesimpulannya terdapat 
heteroskedastisitas (varian dari residual tidak homogen).

\section{Analisis Regresi Linier Berganda}

Menurut Sugiyono (2014:277), analisis linier berganda bertujuan unuk meramalkan bagaimana keadaan (naik turunnya) variabel dependen (kriterium), bila dua atau lebih variabel independen sebagai faktor prediator dimanipulasi (dinaik turunkan nilainya). Jadi analisis regresi berganda akan dilakukan bila jumlah variabel independennya minimal dua.

\section{Analisis Korelasi}

Analisis korelasi terbagi menjadi dua yaitu analisis korelasi parsial dan simultan. Analisis parsial digunakan untuk mengetahui kekuatan hubungan antara korelasi kedua variabel di mana variabel lainnya dianggap berpengaruh dikendalikan atau dibuat tetap (sebagai variabel kontrol). Sedangkan analisis korelasi berganda digunakan untuk mengetahui derajat atau kekuatan hubungan antara seluruh variabel X terhadap variabel Y secara bersamaan.

\section{Pengujian Hipotesis}

Uji hipotesis terbagi menjadi dua yaitu uji hipotesis parsial (t test) dan simultan ( $\mathrm{F}$ test). Uji $\mathrm{t}$ ( $\mathrm{t}$-test) melakukan pengujian terhadap koefisien regresi secara parsial, pengujian ini dilakukan untu mengetahui signifikansi peran secara parsial antara variabel independen terhadap variabel dependen dengan mengansumsikan bahwa variabel independen lain dianggap konstan. H0 ditolak jika nilai thitung $\geq$ ttabel atau nilai $\operatorname{sig}<\alpha$, artinya terdapat pengaruh yang signifikan. Kemudian pengujian simultan dilakukan untuk mengetahui pengaruh semua variabel independen yang terdapat di dalam model secara bersama-sama (simultan) terhadap variabel dependen. H0 ditolak jika nilai Fhitung $\geq$ Ftabel atau nilai sig $<\alpha$, artinya terdapat pengaruh yang signifikan.

\section{Koefisien Determinasi $(\mathbf{K d})$}

Koefisien determinasi merupakan ukuran untuk mengetahui kesesuaian atau ketepatan antara nilai dugaan atau garis regresi dengan data sampel. Jika Kd mendekati nol (0), maka pengaruh variabel independen terhadap variabel dependen lemah. Sedangkan jika Kd mendekati satu (1), maka pengaruh variabel independen terhadap variabel dependen kuat. 


\section{Hasil Dan Pembahasan}

\section{Karakteristik Responden}

Analisis deskriptif karakteristik responden yaitu berupa frekuensi dan presentase responden penelitian yang ditinjau dari jenis kelamin, usia, lama bekerja, pendidikan terakhir, dan juga statusnya.

\begin{tabular}{|c|c|c|}
\hline Profil & Frekuensi & $\%$ \\
\hline \multicolumn{3}{|l|}{ Jenis Kelamin } \\
\hline Laki-laki & 58 & $85 \%$ \\
\hline Perempuan & 10 & $15 \%$ \\
\hline \multicolumn{3}{|l|}{ Usia } \\
\hline $20-30$ th & 17 & $25 \%$ \\
\hline $31-40$ th & 29 & $42 \%$ \\
\hline $41-50$ th & 18 & $27 \%$ \\
\hline$>50$ th & 4 & $6 \%$ \\
\hline \multicolumn{3}{|l|}{ Lama Bekerja } \\
\hline$<5$ tahun & 4 & $7 \%$ \\
\hline 5 - 10 tahun & 10 & $14 \%$ \\
\hline 10 - 15 tahun & 12 & $17 \%$ \\
\hline 15 - 20 tahun & 22 & $32 \%$ \\
\hline 20 - 25 tahun & 15 & $22 \%$ \\
\hline$>25$ tahun & 5 & $8 \%$ \\
\hline \multicolumn{3}{|l|}{ Pendidikan } \\
\hline SMA/SMK & 50 & $74 \%$ \\
\hline Diploma (D3) & 1 & $1 \%$ \\
\hline Sarjana (S1) & 17 & $25 \%$ \\
\hline \multicolumn{3}{|l|}{ Status } \\
\hline Menikah & 61 & $90 \%$ \\
\hline Belum Menikah & 7 & $10 \%$ \\
\hline Pernah Menikah & 0 & $0 \%$ \\
\hline Total & 68 & $100 \%$ \\
\hline
\end{tabular}

Dari tabel itu didapatkan bahwa karyawan yang menjadi responden dalam penelitian ini yang mendominasi sampel penelitian ialah responden dengan jenis kelamin laki - laki sebanyak 58 orang. Responden yang berusia 31 - 40 tahun sebanyak 29 orang. Responden yang telah bekerja di PT. Liku Telaga selama 1520 tahun sebanyak 22 orang. Responden dengan pendidikan terakhir SMA/SMK sebanyak 50 orang. Responden dengan dengan status menikah sebanyak 61 orang. 


\section{Uji Instrumen Penelitian}

Uji instrumen penelitian ini terdiri dari dua macam yaitu uji validitas dan reliabilitas.

Tabel 3. Hasil Uji Instrumen

\begin{tabular}{|c|c|c|c|}
\hline Indikator & rhitung & Sig. & $\begin{array}{c}\text { Cronbach's } \\
\text { Alpha }\end{array}$ \\
\hline \multicolumn{4}{|l|}{ Shift Kerja } \\
\hline Shift1 & 0.886 & 0.000 & \multirow{4}{*}{0.778} \\
\hline Shift2 & 0.896 & 0.000 & \\
\hline Shift3 & 0.888 & 0.000 & \\
\hline Shift4 & 0.448 & 0.000 & \\
\hline \multicolumn{4}{|l|}{ Stres Kerja } \\
\hline Stres1 & 0.538 & 0.000 & \multirow{17}{*}{0.904} \\
\hline Stres2 & 0.587 & 0.000 & \\
\hline Stres3 & 0.518 & 0.000 & \\
\hline Stres4 & 0.654 & 0.000 & \\
\hline Stres5 & 0.663 & 0.000 & \\
\hline Stres6 & 0.666 & 0.000 & \\
\hline Stres7 & 0.705 & 0.000 & \\
\hline Stres8 & 0.838 & 0.000 & \\
\hline Stres9 & 0.809 & 0.000 & \\
\hline Stres10 & 0.351 & 0.000 & \\
\hline Stres11 & 0.437 & 0.000 & \\
\hline Stres12 & 0.375 & 0.002 & \\
\hline Stres13 & 0.754 & 0.000 & \\
\hline Stres14 & 0.726 & 0.000 & \\
\hline Stres15 & 0.785 & 0.000 & \\
\hline Stres16 & 0.662 & 0.000 & \\
\hline Stres17 & 0.827 & 0.000 & \\
\hline \multicolumn{4}{|c|}{ Lingkungan Kerja } \\
\hline Lingkungan1 & 0.805 & 0.000 & \multirow{6}{*}{0.917} \\
\hline Lingkungan2 & 0.813 & 0.000 & \\
\hline Lingkungan3 & 0.860 & 0.000 & \\
\hline Lingkungan4 & 0.891 & 0.000 & \\
\hline Lingkungan5 & 0.791 & 0.000 & \\
\hline Lingkungan6 & 0.890 & 0.000 & \\
\hline \multicolumn{4}{|c|}{ Kinerja Karyawan } \\
\hline Kinerja1 & 0.642 & 0.000 & \multirow{4}{*}{0.869} \\
\hline Kinerja2 & 0.582 & 0.000 & \\
\hline Kinerja3 & 0.650 & 0.000 & \\
\hline Kinerja4 & 0.436 & 0.000 & \\
\hline
\end{tabular}




\begin{tabular}{|c|c|c|c|}
\hline Indikator & $r_{\text {hitung }}$ & Sig. & $\begin{array}{c}\text { Cronbach's } \\
\text { Alpha }\end{array}$ \\
\hline Kinerja5 & 0.633 & 0.000 & \\
\hline Kinerja6 & 0.566 & 0.000 & \\
\hline Kinerja7 & 0.682 & 0.000 & \\
\hline Kinerja8 & 0.530 & 0.000 & \\
\hline Kinerja9 & 0.627 & 0.000 & \\
\hline Kinerja10 & 0.496 & 0.000 & \\
\hline Kinerja11 & 0.648 & 0.000 & \\
\hline Kinerja12 & 0.697 & 0.000 & \\
\hline Kinerja13 & 0.786 & 0.000 & \\
\hline Kinerja14 & 0.729 & 0.000 & \\
\hline
\end{tabular}

Dari tabel di atas didapatkan nilai rhitung dari keseluruhan indikator penyusun masing-masing variabel penelitian lebih dari nilai rtabel sebesar 0.2387 dan nilai signifikansi keseluruhan indikator kurang dari 0.05. Sehingga dapat disimpulkan bahwa semua indikator yang mengukur variabel shift kerja, stres kerja, lingkungan kerja, dan kinerja karyawan telah valid sehingga mampu mengukur dengan baik apa yang diteliti. Lalu untuk uji reliabilitas diperoleh nilai Cronbach's Alpha pada variabel kinerja karyawan lebih dari pada 0.60 sehingga dapat disimpulkan jika variabel yang digunakan dapat dipercaya dan diandalkan sebagai alat pengumpul data.

\section{Uji Asumsi Klasik}

Sebelum dilakukan pengujian hipotesis terlebih dahulu akan dilakukan pengujian asumsi klasik sebagai berikut:

1. Normalitas

Hasil uji normalitas adalah sebagai berikut:

Tabel 4. Uji Normalitas

\begin{tabular}{|c|c|c|}
\hline $\begin{array}{c}\text { Kolmogorov- } \\
\text { Smirnov } Z\end{array}$ & Signifikansi & Kesimpulan \\
\hline 0.579 & 0.891 & Normal \\
\hline Sumber: Data Primer Diolah (2019)
\end{tabular}

Tabel di atas menyajikan hasil uji Kolmogorov-smirnov dari residual model. Dari tabel itu didapatkan nilai signifikansi sebesar 0.891 lebih besar dari pada 0.05 sehingga dapat disimpulkan jika data regresi terdistribusi normal. 
2. Multikolinearitas

Hasil uji multikolinearitas adalah sebagai berikut:

Tabel 5. Uji Multikolinearitas

\begin{tabular}{|l|c|c|}
\hline \multicolumn{1}{|c|}{ Variabel } & Toleransi & VIF \\
\hline Shift kerja & 0.943 & 1.061 \\
\hline Stres kerja & 0.891 & 1.123 \\
\hline Lingkungan kerja & 0.858 & 1.166 \\
\hline \multicolumn{2}{|l|}{ Sumber: Data Primer Diolah (2019) } \\
\end{tabular}

Dari tabel itu didapatkan nilai toleransi dari variabel shift kerja, stres kerja, dan lingkungan kerja masing-masing sebesar 0.943, 0.891, dan 0.858 lebih dari 0.10 dengan nilai VIF dari kedua variabel tersebut masing-masing ialah sebesar 1.061, 1.123, dan 1.166 kurang dari 10 maka dapat disimpulkan bahwa model regresi yang terbentuk tidak terdeteksi adanya multikolinieritas, sehingga asumsi non multikolinearitas terpenuhi.

3. Heteroskedastisitas

Hasil uji heteroskedastisitas adalah sebagai berikut:

Tabel 6. Hasil Uji Rank Spearman

\begin{tabular}{|l|l|c|}
\hline \multicolumn{2}{|c|}{} & Residual \\
\hline \multirow{4}{*}{ Shift kerja } & Correlation Coef. & 0,001 \\
\cline { 2 - 3 } & Sig. (2-tailed) & 0,995 \\
\cline { 2 - 3 } & $\mathrm{N}$ & 68 \\
\hline \multirow{4}{*}{ Stres kerja } & Correlation Coef. & 0,002 \\
\cline { 2 - 3 } & Sig. (2-tailed) & 0,986 \\
\cline { 2 - 3 } & $\mathrm{N}$ & 68 \\
\hline \multirow{2}{*}{$\begin{array}{l}\text { Lingkungan } \\
\text { kerja }\end{array}$} & Correlation Coef. & 0,127 \\
\cline { 2 - 3 } & Sig. (2-tailed) & 0,302 \\
\cline { 2 - 3 } & $\mathrm{N}$ & 68 \\
\hline \multirow{2}{*}{ Sumber: Data Primer Diolah (2019) } &
\end{tabular}

Dari tabel itu didapatkan bahwa variabel shift kerja, stres kerja, dan lingkungan kerja memiliki pvalue (Sig, (2-tailed)) lebih dari 0,05 yang berarti tidak signifikan. Maka dapat disimpulkan bahwa tidak terdapat heteroskedastisitas pada residual model (varian dari residual homogen).

\section{Model Regresi}

Model regresi dari pengaruh shift kerja, stres kerja, dan lingkungan kerja terhadap kinerja karyawan PT. Liku Telaga ialah: 


$$
Y=2,760+0,025 X_{1}-0,174 X_{2}+0,446 X_{3}+e
$$

Keterangan:

$\mathrm{Y} \quad=$ Kinerja karyawan

$\mathrm{X} 1=$ Shift kerja

$\mathrm{X} 2=$ Stres kerja

X3 = Lingkungan kerja

e $\quad$ error model

Model di atas menunjukkan bahwa koefisien regresi shift kerja dan lingkungan kerja bernilai positif, sehingga apabila shift kerja dan lingkungan kerja semakin baik, maka kinerja karyawan juga akan semakin baik. Sedangkan koefisien regresi dari stres kerja bernilai negatif, sehingga apabila stres kerja yang dialami karyawan semakin rendah maka kinerja karyawan itu akan semakin baik.

\section{Analisis Korelasi}

\section{Analisis Korelasi Parsial}

Hasil analisis korelasi parsial adalah sebagai berikut:

Tabel 7. Korelasi Parsial

\begin{tabular}{|l|c|c|}
\hline \multicolumn{1}{|c|}{ Variabel } & $\begin{array}{c}\text { Partial } \\
\text { Correlation }\end{array}$ & $\begin{array}{c}\text { Tingkat } \\
\text { Hubungan }\end{array}$ \\
\hline Shift kerja & 0,093 & $\begin{array}{c}\text { Sangat } \\
\text { Rendah }\end{array}$ \\
\hline Stres kerja & $-0,418$ & Sedang \\
\hline $\begin{array}{l}\text { Lingkungan } \\
\text { kerja }\end{array}$ & 0,768 & Kuat \\
\hline \multicolumn{2}{|l}{ Sumber: Data Primer Diolah (2019) } \\
\hline
\end{tabular}

Dari tabel itu didapatkan nilai korelasi shift kerja ialah sebesar 0,093 dan tingkat hubungannya dengan kinerja karyawan sangat rendah. Lalu nilai korelasi dari stres kerja ialah sebesar 0,418 dan tingkat hubungannya dengan kinerja karyawan sedang. Kemudian nilai korelasi lingkungan kerja adalah sebesar 0,768 dan tingkat hubungannya dengan kinerja karyawan kuat.

\section{Analisis Korelasi Simultan}

Dari hasil analisis, diperoleh nilai korelasi simultan sebesar 0,790 yang mana nilai korelasi ini berada pada rentang 0,60 hingga 0,799 yang berarti hubungan variabel independen shift kerja, stres kerja, dan lingkungan kerja 
terhadap variabel dependen kinerja karyawan tergolong kuat.

\section{Pengujian Hipotesis}

Pengujian hipotesis dalam penelitian dilakukan melalui dua cara yaitu pengujian hipotesis secara secara parsial dan pengujian hipotesis secara simultan.

1. Uji t (Uji Parsial)

Hasil uji hipotesis secara parsial sebagaimana tertera pada tabel berikut:

Tabel 8. Hasil Uji Parsial

\begin{tabular}{|l|c|c|}
\hline \multicolumn{1}{|c|}{ Variabel } & thitung & Signifikansi \\
\hline Shift kerja & 0,749 & 0,457 \\
\hline Stres kerja & $-2,276$ & 0,026 \\
\hline $\begin{array}{l}\text { Lingkungan } \\
\text { kerja }\end{array}$ & 8,382 & 0,000 \\
\hline
\end{tabular}

Dari tabel itu didapatkan nilai signifikansi dari uji parsial (t) pada masingmasing variabel stres kerja dan lingkungan kerja adalah 0,026 dan 0,000 kurang dari nilai signifikansi ketetapan sebesar 0,05. Hal tersebut berarti bahwa stres kerja memiliki pengaruh yang signifikan terhadap kinerja karyawan PT. Liku Telaga. Begitu pula untuk variabel lingkungan kerja juga memiliki pengaruh yang signifikan terhadap kinerja karyawan PT. Liku Telaga. Sedangkan untuk variabel shift kerja tidak berpengaruh signifikan terhadap kinerja karyawan PT. Liku Telaga, karena nilai signifikansi yang diperoleh lebih dari nilai signifikansi ketetapan sebesar 0.05 .

2. Uji F (Uji Simultan)

Hasil uji hipotesis secara simultan adalah sebagai berikut:

Tabel 9. Hasil Uji Simultan

ANOVA $^{\mathrm{a}}$

\begin{tabular}{|l|r|r|r|r|r|}
\hline Model & $\begin{array}{c}\text { Sum of } \\
\text { Squares }\end{array}$ & df & $\begin{array}{c}\text { Mean } \\
\text { Square }\end{array}$ & $F$ & Sig. \\
\hline Regression & 8.601 & 3 & 2.867 & 35.426 & $.000^{\mathrm{b}}$ \\
Residual & 5.180 & 64 & .081 & & \\
Total & 13.781 & 67 & & & \\
\hline
\end{tabular}

a. Dependent Variable: Kinerja Karyawan

b. Predictors: (Constant), Lingkungan Kerja, Shift Kerja,

Stres Kerja

Sumber: Data Primer Diolah (2019)

Dari tabel itu didapatkan nilai $\mathrm{F}$ hitung sebesar 35,426 > F tabel sebesar 
2,478 dan nilai signifikansi dari uji ini sebesar $0,000<0,05$, sehingga dapat disimpulkan bahwa secara bersama-sama variabel shift kerja, stres kerja, dan lingkungan kerja berpengaruh signifikan terhadap kinerja karyawan PT. Liku Telaga.

\section{Koefisien Determinasi}

Nilai koefisien determinasi $\left(\mathrm{R}^{2}\right)$ dari model regresi pengaruh shift kerja, stres kerja, dan lingkungan kerja terhadap kinerja karyawan ialah sebesar 0,624 atau setara dengan $62,4 \%$ yang berarti bahwa variabel shift kerja, stres kerja, dan lingkungan kerja dapat menjelaskan dan mempengaruhi variabel kinerja karyawan sebesar $62,4 \%$. Sedangkan sisanya sebesar $37,6 \%$ dapat dijelaskan oleh variabel lain yang tidak digunakan dalam penelitian ini.

Berdasarkan analisis di atas, maka dapat ditarik ikhtisar penerimaan atau penolakan hipotesis penelitian seperti yang tersaji dalam Tabel 10, di mana keempat hipotesis diterima karena semua variabel independen berpengaruh terhadap variabel dependen.

Tabel 10. Ikhtisar Hasil Analisis (Penolakan/Penerimaan Hipotesis)

\begin{tabular}{|c|l|c|}
\hline \multicolumn{1}{|c|}{ Hipotesis } & Ditolak/ Diterima \\
\hline H1 & $\begin{array}{l}\text { Shift kerja diduga berpengaruh terhadap kinerja } \\
\text { karyawan di PT. Liku Telaga }\end{array}$ & Diterima \\
\hline H2 & $\begin{array}{l}\text { Stres kerja diduga berpengaruh terhadap kinerja } \\
\text { karyawan di PT. Liku Telaga }\end{array}$ & Diterima \\
\hline H3 & $\begin{array}{l}\text { Lingkungan kerja diduga berpengaruh terhadap } \\
\text { kinerja karyawan di PT. Liku Telaga }\end{array}$ & Diterima \\
\hline H4 & $\begin{array}{l}\text { Shift kerja, stres kerja dan lingkungan kerja secara } \\
\text { simultan berpengaruh terhadap kinerja karyawan } \\
\text { di PT. Liku Telaga }\end{array}$ & Diterima \\
\hline
\end{tabular}

\section{Pembahasan}

\section{Pengaruh Shift Kerja Terhadap Kinerja Karyawan PT. Liku Telaga}

Nilai koefisien regresi shift kerja adalah sebesar 0,025 dengan nilai signifikansi dari uji t sebesar 0,457 lebih dari nilai signifikansi ketetapan sebesar 0,05. Hasil itu menunjukkan bahwa shift kerja memiliki pengaruh yang positif namun tidak signifikan terhadap kinerja karyawan, yang berarti bahwa apabila shift kerja karyawan di PT. Liku Telaga semakin baik, maka kinerja karyawan di 
perusahaan itu akan semakin baik. Akan tetapi pengaruh shift kerja terhadap kinerja karyawan tidak signifikan, jadi sesuai atau tidaknya pembagian shift kerja dengan keinginan karyawan tidak begitu berefek pada kinerja mereka, sehingga hipotesis yang menyatakan bahwa shift kerja berpengaruh terhadap kinerja karyawan PT Liku Telaga tidak terbukti dan tidak dapat diterima.

Menurut Adnan (2002), sistem shift kerja dapat berdampak positif dan negatif. Dampak positif sistem shift kerja adalah memaksimalkan sumber daya yang ada, memberikan lingkungan kerja yang sepi khususnya shift malam, dan memberikan waktu libur yang banyak. Sedangkan dampak negatif sistem shift kerja adalah penurunan kinerja, keselamatan kerja, dan masalah kesehatan. Tidak semua orang dapat menyesuaikan diri dengan sistem shift kerja karena membutuhkan banyak penyesuaian waktu, seperti waktu tidur, waktu makan dan waktu berkumpul bersama keluarga. Kinerja karyawan dapat ditentukan oleh berbagai faktor yang dialami individu dalam bekerja. Pada penelitian ini, diharapkan akan mendapatkan hubungan antara shift kerja, stres kerja dan lingkungan kerja terhadap kinerja karyawan.

Penelitian terdahulu oleh Coffey, et. al. (1988), didapatkan pengaruh shift kerja terhadap kinerja dan stes terhadap pekerjaan pada perawat di rumah sakit. Hasil penelitian Coffey, et. al., (1988) kinerja perawat tertinggi pada siang hari, diikuti dengan shift malam, shift sore dan pergantian shift. Stres terhadap pekerjaan juga didapatkan yang tertinggi adalah pergantian shift, diikuti dengan shift pada sore hari, siang hari dan malam hari. Dengan demikian, shift kerja berpengaruh terhadap kinerja dan stres yang berkaitan dengan pekerjaan serta bukan faktor lain. Selanjutnya penelitian Chou dan Hsieh (2010) yang menunjukkan bahwa khususnya shift malam dapat memiliki dampak negatif pada kualitas tidur dan secara moderat menyebabkan kinerja kerja yang buruk karena dapat menyebabkan gangguan pada normal circadian rhythms dari fungsi psikofisiologis sehingga mengganggu kinerja dan efisiensi.

\section{Pengaruh Stres Kerja Terhadap Kinerja Karyawan PT. Liku Telaga}

Nilai koefisien regresi stres kerja adalah sebesar -0,174 dengan nilai signifikansi dari uji t sebesar 0,026 kurang dari nilai singnifikansi ketetapan sebesar 
0,05. Hasil itu menunjukkan bahwa stres kerja memiliki pengaruh signifikan namun negatif terhadap kinerja karyawan, yang berarti bahwa apabila stres kerja yang dialami karyawan di PT. Liku Telaga semakin rendah, maka kinerja karyawan di perusahaan itu akan semakin baik, sehingga hipotesis yang menyatakan bahwa stres kerja berpengaruh terhadap kinerja karyawan PT Liku Telaga telah terbukti dan diterima.

Dalam kehidupan modern yang makin kompleks, manusia akan cenderung mengalami stres apabila individu kurang mampu mengadaptasikan keinginan dengan kenyataan yang ada, baik kenyataan yang ada di dalam maupun di luar dirinya. Segala macam bentuk stres pada dasarnya disebabkan oleh kurang mengertinya manusia akan keterbatasannya. Ketidakmampuan untuk melawan keterbatasan inilah yang akan menimbulkan frustasi, konflik, gelisah dan rasa bersalah yang merupakan tipe-tipe dasar stres (Luthans, 2006:439). Menurut Anatan dan Ellitan (2007:54), konflik di tempat kerja, pemberian beban kerja yang terlalu berlebihan terhadap karyawan dapat menimbulkan stres yang berkepanjangan, yaitu kondisi atau keadaan yang tidak menyenangkan yang dihadapi oleh setiap orang baik secara fisik maupun mental.

Penelitian terkait hubungan stres kerja terhadap kinerja karyawan dilakukan oleh Khuong dan Yen (2016) yang menunjukkan bahwa stres kerja yang berpengaruh negatif terhadap kinerja karyawan. Penelitian ini juga menemukan bahwa pengembangan karir tidak secara langsung mempengaruhi kinerja karyawan, tetapi secara tidak langsung melalui stres kerja. Lalu penelitian yang dilakukan Dar, et. al., (2011) tentang pengaruh stres terhadap kinerja karyawan di sektor bisnis Pakistan, juga mendapatkan hasil yang hampir sama dengan penelitian oleh Khuong dan Yen (2016). Menurut Dar, et. al., (2011), kinerja dapat dilihat sebagai aktivitas di mana seseorang dapat menyelesaikan tugas yang diberikan dengan sukses, sesuai dengan batasan dalam pemanfaatan sumber daya yang tersedia. Penelitian ini mengungkapkan hubungan negatif antara stres kerja terhadap kinerja karyawan dan menunjukkan bahwa stres kerja secara signifikan mengurangi kinerja pekerjaan karyawan. Selanjutnya pengaruh stres kerja terhadap kinerja karyawan juga dilakukan Ahmed dan Ramzan (2013) pada sektor perbankan di Pakistan. Hasil 
penelitian menunjukkan bahwa signifikan dengan korelasi negatif antara stres kerja dan kinerja. Hal tersebut dapat diartikan bahwa stres kerja secara signifikan mengurangi kinerja pekerja.

Penelitian Altangerel, et. al., (2015) menemukan bahwa kelebihan pekerjaan adalah alasan utama stres dan berdampak pada berkurangnya produktivitas dan kehilangan minat dalam bekerja. Selain itu, masalah kesehatan seperti mata yang tegang, pusing dan gangguan tidur juga disebabkan oleh stres kerja. Berdasarkan penelitian, parameter pendidikan, pengalaman dan gaji setiap bulan signifikan secara statistik dan memberi dampak positif pada kinerja karyawan. Hal berbeda ditunjukkan bahwa usia, banyaknya jumlah anggota keluarga, tidak adanya waktu bersantai yang diberikan pada karyawan selama jam kerja dan beban kerja secara statistik signifikan negatif pada kinerja karyawan.

\section{Pengaruh Lingkungan Kerja Terhadap Kinerja Karyawan PT. Liku Telaga}

Nilai koefisien regresi lingkungan kerja adalah sebesar 0,446 dengan nilai signifikansi dari uji t sebesar 0,000 kurang dari nilai signifikansi ketetapan sebesar 0,05. Hasil itu menunjukkan bahwa lingkungan kerja memiliki pengaruh yang positif dan signifikan terhadap kinerja karyawan, yang berarti bahwa apabila lingkungan kerja di PT. Liku Telaga semakin baik, maka kinerja karyawan si perusahaan itu juga akan semakin baik, sehingga hipotesis yang menyatakan bahwa lingkungan kerja berpengaruh terhadap kinerja karyawan PT Liku Telaga telah terbukti dan diterima.

Menurut Nitisemito (2011), lingkungan kerja merupakan keseluruhan alat perkakas yang dihadapi, lingkungan sekitarnya di mana seseorang bekerja, metode kerjanya, serta pengaturan kerjanya baik sebagai perseorangan mapun sebagai kelompok. Jika ruangan kerja tidak nyaman, panas, sirkulasi udara kuranga memadai, ruangan kerja terlalu padat, kurang bersih, berisik, tentu besar pengaruhnya pada kenyamanan kerja karyawan. Perlu dilakukan pemeliharaan prasarana fisik seperti kebersihan yang selalu terjaga, penerangan cahaya yang cukup, ventilasi udara, suara musik dan tata ruang tempat kerja. Kondisi lingkungan kerja yang baik akan mendorong inisiatif dan kreativitas sehingga menciptakan antusiasme untuk bersatu dalam organisasi perusahaan untuk mencapai tujuan 
perusahaan dengan meningkatkan kinerja karyawan.

Penelitian pengaruh lingkungan kerja terhadap kinerja karyawan dilakukan oleh Malik, et.al., (2011) di Pakistan. Hasil korelasi Pearson menunjukkan bahwa semua variabel independen memiliki hubungan yang kuat dan signifikan dengan kinerja karyawan, terutama kondisi kerja fisik yang mencerminkan hubungan positif dan signifikan paling kuat. Sedangkan hasil analisa regresi menunjukkan bahwa kinerja karyawan sebagian besar tergantung pada kondisi kerja fisik, pelatihan pengembangan dan praktek komunikasi. Hal tersebut sesuai dengan hipotesa awal Malik, et. al., (2011). Lingkungan kerja berdampak pada kemampuan individu untuk bekerja dengan aman, kompeten dan sesuai dengan target kinerja operasional. Indikator lingkungan kerja pada penelitian ini meliput: dukungan sosial, kondisi kerja fisik, karakterisasi pekerjaan, pelatihan dan pengembangan dan pelatihan komunikasi. Penelitian lainnya oleh Al-Omari dan Okasheh (2017) di Jordan. Elemen lingkungan kerja yang diteliti adalah kebisingan, suhu udara, penerangan, warna ruangan dan kepuasan kerja. Dari penelitian, ditemukan kendala situasional seperti kebisingan, fasilitas material kerja, ventilasi dan penerangan adalah kondisi lingkungan kerja utama yang memiliki dampak negatif pada kinerja karyawan dan harus mendapat perhatian khusus. Massoudi dan Hamdi (2017) menganalisa lingkungan kerja bank swasta asing yang beroperasi di wilayah Kurdistan Irak dan menguji hubungan antara kondisi fisik tempat kerja terhadap produktivitas karyawan. Hasil penelitian menunjukkan bahwa adanya hubungan antara lingkungan kantor dan produktivitas karyawan dan ditunjukkan dengan $80 \%$ dari responden. Selanjutnya penelitian hubungan antara desain tempat kerja dan kinerja dilakukan Mendis (2016) pada karyawan tingkat operasional di industri pakaian Srilanka. Hasil penelitian menunjukkan bahwa desain tempat kerja berkorelasi signifikan dan berhubungan positif dengan kinerja karyawan. Menurut Nzewi (2018), terdapat hubungan positif yang signifikan antara ergonomis dan kepuasan kerja. Ketika mesin diatur sedemikian rupa agar sesuai dan memberi kenyamanan karyawan, karyawan akan lebih betah berada di tempat kerja. Untuk peralatan yang lebih diperhatikan meningkatkan kinerja karyawan. 


\section{Pengaruh Shift Kerja, Stres Kerja, dan Lingkungan Kerja Terhadap Kinerja Karyawan PT. Liku Telaga}

Besar pengaruh shift kerja, stres kerja, dan lingkungan kerja terhadap kinerja karyawan adalah 0,624 atau setara dengan $62,4 \%$, yang berarti bahwa variabel shift kerja, stres kerja, dan lingkungan kerja dapat menjelaskan dan mempengaruhi variabel kinerja karyawan sebesar $62,4 \%$. Sedangkan sisanya sebesar 37,6\% dapat dijelaskan oleh variabel lain yang tidak digunakan dalam penelitian ini. Kemudian untuk hasil pengujian simultan diperoleh $F$ hitung sebesar 35.426 dengan nilai signifikansi sebesar 0.000 kurang dari nilai signifikansi ketetapan sebesar 0.05. Hasil itu menunjukkan bahwa shift kerja, stres kerja, dan lingkungan kerja secara simultan memiliki pengaruh yang signifikan terhadap kinerja karyawan, sehingga hipotesis yang menyatakan bahwa shift kerja, stres kerja, dan lingkungan kerja berpengaruh signfikan terhadap kinerja karyawan PT Liku Telaga telah terbukti dan diterima.

\section{Kesimpulan}

Berdasarkan hasil penelitian yang telah dilakukan oleh peneliti, maka dapat ditarik beberapa kesimpulan sebagai berikut:

1. Shift kerja berpengaruh tidak signifikan dan positif terhadap kinerja karyawan PT. Liku Telaga. Dengan demikian, shift kerja tidak berdampak pada kinerja karyawan.

2. Stres kerja berpengaruh sigifikan dan negatif terhadap kinerja karyawan PT.

Liku Telaga. Hal tersebut menjelaskan bahwa menurunkan tingkat stres kerja karyawan, maka kinerja karyawan PT. Liku Telaga akan meningkat signifikan.

3. Lingkungan kerja berpengaruh signifikan dan positif terhadap kinerja karyawan. Hal tersebut menjelaskan bahwa meningkatkan kondisi lingkungan kerja, maka kinerja karyawan PT. Liku Telaga akan meningkat signifikan.

4. Shift kerja, stres kerja dan lingkungan kerja secara simultan berpengaruh signifikan terhadap kinerja karyawan PT. Liku Telaga. 


\section{DAFTAR PUSTAKA}

Adnan. (2002). Hubungan Antara Tipe Kepribadian dan Tipe Circadiandengan sikap Terhadap Kerja Shift. Diakses dari http://garuda.dikti.go.id/jurnal/detil/id/0:8016/9/pengarang:irma/offset/0/lim it/15.pdf

Ahmed, A. and Muhammad Ramzan. 2013. Effect of Job Stress on Employees Job Performance A Study on Banking Sector of Pakistan, IOSR Journal of Business and Management,11,61-68.

Al-Omari, K. and H. Okasheh; 2017. The Influence of Work Environment on Job Performance: A Case Study of Engineering Company in Jordan. International Journal of Applied Engineering Research, 12, 15544-15550.

Altangerel, O; W. Ruimei; E. Elahi; B. Dash. 2015. Investigating the Effect of Job Stress on Performance Of Employees. International Journal of Scientific \& Technology Research, 4, 276-280.

Anatan, Lina \& Ellitan, Lena. (2007). Manajemen Sumber Daya Manusia Dalam Bisnis Modern. Bandung: Alfabeta.

Chou, A. W. M and C.L. Hsieh. 2010. The Impact of Shift Work Implementation on Sleeping Quality and Job Performance: A Case Study of Semi-conductor Manufacturing Company. The $40^{\text {th }}$ International Conference on Computers \& Industrial Engineering.

Coffey, L.C.; J. K. Skipper Jr.; F. D. Jung. 1988. Nurses and Shift Work: Effect on Job Performance and Job-Related Stress. Journal of Advanced Nursing, 13, 245-254.

Dar. L.; A. Akmal; M. A. Naseem; K. U. D. Khan. 2011. Impact of Stress on Employees Job Performance in Business Sector of Pakistan. Global Journal of Management and Business Research, 11(6), Ver. 1.

Gujarati, D. N. (2012). Dasar-dasar Ekonometrika, Terjemahan Mangunsong, R. C. Edisi Kelima. Jakarta: Salemba Empat.

Khuong, M.N. and Yen, V. H. 2016. Investigate the Effect of Job Stress on Employee Job Performance - A Case Study at Dong Xuyen Industrial Zone, Vietnam. International Journal of Trade, 7(2), 31-37. 
Kroll, Rainer. 2010. Evaluation of The Effect of Shift Work Assignment: A Survey of Motivation in Police Officers. Journal Proquest LLC New York.

Kuncoro, M. (2003). Metode Riset Untuk Bisnis \& Ekonomi. Jakarta: Erlangga.

Luthans, Fred. (2006). Perilaku Organisasi, Edisi Sepuluh. Yogyakarta: PT. Andi.

Malik, M. I.; A. Ahmad.; S. F. Gomez and M. Ali. 2011. A Study of Work Environment and Employees' Performance in Pakistan. African Journal of Bussiness Management, 5(34), 13227-13232.

Mangkunegara, A.A, Anwar Prabu. 2009. Manajemen Sumber Daya Manusia Perusahaan. Bandung: PT. Remaja Rosdakarya.

Massoudi, A. H. and S. S. A. Hamdi. 2017. The Consequence of Work Environment on Employees Productivity. IOSR Journal of Business and Management, 19(1), P. 35-42.

Mariam, Rani. (2009). Pengaruh Gaya Kepemimpinan dan Budaya Organisasi Terhadap Kinerja Karyawan Melalui Kepuasan Kerja Karyawan Studi Pada Kantor Pusat Asuransi Jasa Indonesia. Master Thesis. Program Pascasarjana, Universitas Diponegoro.

Mendis, M.V.S. 2016. Workplace Design and Job Performance: A Study of Operational Level Employees in the Apparel Industry of Sri Lanka. International Journal of Scientific and Research Publications, 6(12), P. 148153.

Nitisemito, Alex, S. (2011). Manajemen Personalia (Manajemen Sumber Daya Manusia), Edisi Kelima, Cetakan Keempat Belas. Ghalia.

Nurhidayah, S. 2018. Pengaruh Lingkungan Kerja terhadap Kinerja Karyawan dengan Motibasi Kerja sebagai Variabel Mediasi (Studi Kasus CV. Fajar Nusantara Jaya Serengan, Surakarta). Skripsi. Tidak Diterbitkan. Fakutas Ekonomi dan Bisnis Islam. Institut Agama Islam Negeri Surakarta: Surakarta.

Nzewi, H.N.; A. Augustine; I. Mohammed and O. Godson. 2018. Physical Work Environment and Employee Performance in Selected Brewing Firms in Anambra State, Nigeria. Journal of Good Governance and Sustainable Development in Africa, 4(2), P. 131-145.

Pawirosumarto, S.; P.K. Sarjana and R. Gunawan. 2016. The Effect of Work 
Environment, Leadership Style, and Organizational Culture Towards Job Satisfaction and Its Implication Towards Employee Performance in Parador Hotels and Resorts, Indonesia. International Journal of Law and Management, 59(6), P. 1337-1358.

Satrio, P. 2015. Pengaruh Shift Kerja dan Stres Kerja terhadap Kinerja Pramuniaga terhadap Kinerja Pramuniaga di PT. Circleka Indonesia Utama Cabang Yogyakarta. Skripsi. Tidak Diterbitkan. Fakultas Ekonomi. Universitas Negeri Yogyakarta: Yogyakarta.

Sugiyono, 2014. Metode Penelitian Pendidikan Pendekatan Kuantitif, Kualitatif, dan $R \& D$. Bandung: Alfabeta.

Umar, Husein. (2005). Metode Penelitian Untuk Thesis dan Bisnis. Jakarta: Grafindo.

Vanagas, G. (2005). The Factors Associated to Psycholosocial Stress among General Practitioners in Lithuania. Cross-Sectional Study. BMC Health Services Research, 5 (1), 1-8. 